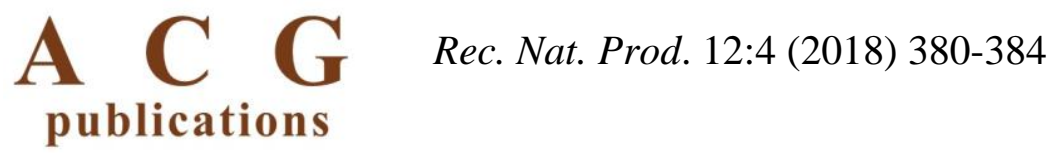

\title{
Chemical Constituents Isolated from Lycium shawii and their Chemotaxonomic Significance
}

\author{
Najeeb Ur Rehman ${ }^{\oplus 1}$, Hidayat Hussain ${ }^{* 1}$, Samia Ahmed Al-Riyami ${ }^{\oplus 1}$, \\ Ivan. R. Green ${ }^{\oplus 2}$ and Ahmed Al-Harrasi: ${ }^{* \oplus 1}$ \\ ${ }^{1}$ UoN Chair of Oman's Medicinal Plants and Marine Natural Products, University of Nizwa, P.O Box \\ 33, Postal Code 616, Birkat Al Mauz, Nizwa, Sultanate of Oman \\ ${ }^{2}$ Department of Chemistry and Polymer Science, University of Stellenbosch, P/Bag X1, Matieland, \\ 7602, South Africa
}

(Received September 29, 2017; Revised November 13, 2017; Accepted November 15, 2017)

\begin{abstract}
Phytochemical investigation of Lycium shawii Roem. \& Schult provided fourteen compounds, including lyciumate (1), dehydrocostus lactone (2), costunolide (3), catechin (4), lyciumaside (5), emodin (6), emodin-8- $O$ - $\beta$-D-glucoside (7), aloe-emodin (8), aloe-emodin-8- $O$ - $\beta$-D-glucoside (9), aloe emodin-11- $O$ rhamnoside (10), chrysophanol-8-O- $\beta$-D-glucoside (11), nonacosane-10-ol (12), betulinic acid (13) and $\beta$ sitosterol glucopyranoside (14). The compounds may be classified as three sesquiterpene lactones (1-3), two phenolic compounds (4 and 5), six anthraquinones (6-11), one long chain alcohol (12), one lupane-type triterpenoid (13) and a steroid (14). Compounds 2, 3, 7 and 9-12 are reported here for the first time as isolated from any species of Lycium as well as from the Solanaceae family while compounds $\mathbf{8 , 1 3}$ and 14 are reported to be found for the first time in the genus Lycium. All structural assignments were made by comparing the NMR spectral data of the pure isolates with that published in the quoted literature.
\end{abstract}

Keywords: Lycium shawii; Solanaceae; anthraquinone; sesquiterpene. (C) 2018 ACG Publications. All rights reserved.

\section{Plant source}

Lycium (Solanaceae) comprises of ca. 90 species of thorny shrubs distributed throughout the tropical regions of the world. L. shawii Roem \& Schult is a thorny shrub which is locally known as "Ghasad" and is found in the Sultanate of Oman. The stem bark, L. shawii, was purchased from Nizwa Souq (May, 2015) and identified through a plant taxonomist (Department of Biological Sciences and Chemistry, University of Nizwa, the Sultanate of Oman), where a voucher specimen (BSHR-05/2015) is deposited.

\section{Previous studies}

A previous report by Baghdadi et al. described the presence of rutin, diosgenin, and $\beta$ sitosterol [1], while the current author described the presence of one diacylglycoside and one sesquiterpene lactone from $L$. shawii [2].

\footnotetext{
* Corresponding authors; E-mails: aharrasi@ unizwa.edu.om (A. Al-Harrasi); Phone: +96825446328; hussainchem3@gmail.com (H. Hussain); Phone: +96825446771.
} 


\section{Present Study}

Due to the increasing importance in the use of active agents in plants for medicinal purposes, a more comprehensive phytochemical investigation of $L$. shawii was of paramount importance. The airdried powder material $(640 \mathrm{~g})$ of the stem bark (L. shawii) was extracted with methanol for a couple of weeks. The obtained methanol extract ( $304 \mathrm{~g}$ ) was suspended in water and successively partitioned to provide the following fractions viz., $n$-hexane $(26 \mathrm{~g}), \mathrm{CH}_{2} \mathrm{Cl}_{2}(11 \mathrm{~g})$, EtOAc $(25 \mathrm{~g}), n$-BuOH $(26 \mathrm{~g})$ and aqueous $(44.5 \mathrm{~g})$. The $n$-hexane fraction was loaded on silica gel column chromatography (CC) and eluted with $n$-hexane, followed by increasing concentrations of EtOAc in $n$-hexane $(10,20,30$, and $100 \%)$ to give four fractions $\mathrm{H}_{\mathrm{A}-\mathrm{D}}$. Fraction $\mathrm{H}_{\mathrm{B}}(0.5 \mathrm{~g})$ was further purified by $\mathrm{CC}$ using $n$ hexane:EtOAc (80:20 to 60:40) to provide lyciumate $(1,5 \mathrm{mg})$ [2], dehydrocostus lactone $(2,60 \mathrm{mg})$ and costunolide $(3,45 \mathrm{mg})$ [3], while fraction $\mathrm{H}_{\mathrm{A}}(0.3 \mathrm{~g})$ on further CC purification with $n$ hexane:EtOAc (90:10) as eluent provided nonacosane-10-ol (12, $12 \mathrm{mg})$ [4].

Similarly, the EtOAc fraction $(25 \mathrm{~g})$ was loaded over CC and eluted with a solvent system of increasing polarity, viz., $n$-hexane-EtOAc, EtOAc, EtOAc-MeOH and pure $\mathrm{MeOH}$ to obtained four fractions $\left(\mathrm{E}_{\mathrm{A}-\mathrm{D}}\right)$. Fraction $\mathrm{E}_{\mathrm{B}}$ was further subjected to $\mathrm{CC}$ purification using the eluent system of $n$ hexane:EtOAc (80:20 to 40:60) and afforded catechin $(4,85 \mathrm{mg})$ [5], emodin $(\mathbf{6}, 16 \mathrm{mg})$ [6], aloeemodin $(\mathbf{8}, 60 \mathrm{mg})$ [7], and aloe-emodin-11-O-rhamnoside $(\mathbf{1 0}, 25 \mathrm{mg})$ [8], chrysophanol-8- $O-\beta$-Dglucoside $(\mathbf{1 1}, 9 \mathrm{mg})$ [9], betulinic acid $(\mathbf{1 3}, 30 \mathrm{mg})$ [10] and $\beta$-sitosterol glucopyranoside $(\mathbf{1 4}, 30 \mathrm{mg})$ [11]. Similarly fraction $\mathrm{E}_{\mathrm{C}}$ was further subjected to silica gel CC eluting with $\mathrm{MeOH}$ :EtOAc (10:90) to afford lyciumaside $(5,12 \mathrm{mg})$ [2] while fraction $\mathrm{E}_{\mathrm{D}}$ was loaded directly onto a recycling HPLC system using MeOH:EtOAc (50:50) at a flow rate of $4 \mathrm{~mL} / \mathrm{min}$ and using a UV detector to indicate the active compounds, provided emodin-8- $O-\beta$-D-glucoside $(7,12 \mathrm{mg})$ [7] and aloe-emodin- $8-O-\beta$-D-glucoside (9,9 mg).

\section{Chemotaxonomic Significance}

More than 200 natural products have been reported to be present in the genus Lycium, including the alkaloids viz., cyclopentapyrrolidine, imidazole, piperidine, nortropane, tropane, pyrrole, spermine, in addition to peptides, flavonoids, ceramides, anthraquinones, coumarins, steroids, terpenoids (monoterpenes, diterpenes and triterpenes), organic acids, polysaccharides, carotenoids, cinnamic acid amides, lignans, neo-lignanamides, and lignanamides [12]. In the current investigation, a total of fourteen compounds viz., three sesquiterpene lactones [(lyciumate (1), dehydrocostus lactone (2) and costunolide (3)], two phenolic compounds [(catechin (4) and lyciumaside (5], six anthraquinones/anthraquinone glycosides [(emodin (6), emodin-8-O- $\beta$-D-glucoside (7), aloe-emodin (8), aloe-emodin-8-O- $\beta$-D-glucoside (9), aloe-emodin-11- $O$-rhamnoside (10), chrysophanol-8- $O-\beta$-Dglucoside (11)], one long chain alcohol (nonacosane-10-ol, 12), one lupane-type triterpenoid (betulinic acid, 13), and the steroid ( $\beta$-sitosterol glucopyranoside, 14) have been isolated and identified (Figure 1). Moreover lyciumate (1) and lyciumaside (5) have earlier been identified in L. shawii while compounds 2-4, and 6-14 are reported here for the first time as being isolated from the title plant.

Although the sesquiterpene lactone viz., lyciumate (1) has been identified in the extract of the title plant [2], the sesquiterpene lactones viz., dehydrocostus lactone (2) and costunolide (3) are reported here for the first time to be identified from any species of Lycium as well as from the Solanaceae family. Moreover, no sesquiterpene lactone, to our best knowledge, has been reported from genus Lycium. Our search of the literature revealed that only four sesquiterpenes were reported from $L$. chinense and L. halimifolium [12]. It is well known that sesquiterpene lactones are common in families' viz., Euphorbiaceae, Cactaceae, Solanaceae and Araceae as well as being quite prevalent in the Asteraceae [13]. A further interesting feature of plants of the Solanaceae family is that they produce a distinctive collection of sesquiterpenes described as the phytoalexins [14]. Previously dehydrocostus lactone (2) and costunolide (3) were reported to be isolated from Saussurea lappa Clarke (Compositae) [15], Cichorium intybus L. (Asteraceae) [16]. On the other hand the occurrence of catechin (4) in the title plant is in agreement with similar types of compounds previously reported 
from other Lycium species i.e from L. chinens [17]. Importantly, compound 4 is now reported for the first time as being isolated from the genus Lycium while it has previously been reported to be present in various plants of Solanaceae viz., potato (Solanum tuberosum) [18], Amanaga capsicum, Lycopersicon esculentum Mill, Capsicum annuum [19], and Alchemilla barbatiflora Juz [20]. The diester lyciumaside (5) has previously been reported from the title plant [2].

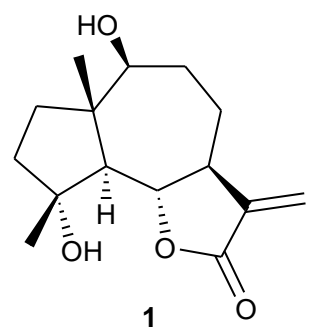<smiles>C=C1CC[C@H]2C(=C)C(=O)O[C@@H]2[C@H]1C</smiles><smiles>C=C1C(=O)O[C@@H](/C=C/C)/C=C/CCC1C</smiles><smiles>[R3]c1cc([R20])c2c(c1)C(=O)c1cc([R])cc(O)c1C2=O</smiles>

6: $\mathrm{R}_{1}=\mathrm{Me}, \mathrm{R}_{2}=\mathrm{H}, \mathrm{R}_{3}=\mathrm{OH}$ 7: $\mathrm{R}_{1}=\mathrm{Me}, \mathrm{R}_{2}=\mathrm{Glc}, \mathrm{R}_{3}=\mathrm{OH}$ 8: $\mathrm{R}_{1}=\mathrm{CH}_{2} \mathrm{OH}, \mathrm{R}_{2}=\mathrm{R}_{3}=\mathrm{H}$ 9: $\mathrm{R}_{1}=\mathrm{CH}_{2} \mathrm{OH}, \mathrm{R}_{2}=\mathrm{Glc}, \mathrm{R}_{3}=\mathrm{H}$ 10: $\mathrm{R}_{1}=\mathrm{CH}_{2} \mathrm{ORha}, \mathrm{R}_{2}=\mathrm{R}_{3}=\mathrm{H}$ 11: $R_{1}=M e, R_{2}=$ Glc, $R_{3}=H$<smiles>Oc1cc(O)c2c(c1)O[C@H](c1ccc(O)c(O)c1)[C@H](O)C2</smiles>

4<smiles>C=C(C)[C@H]1CC[C@]2(C(=O)O)CC[C@]3(C)C(CCC4[C@@]5(C)CC[C@H](O)C(C)(C)C5CC[C@]43C)C12</smiles><smiles>CCCCCCCCCCCCCCCCCCC(O)CCCCCCCC</smiles>

12<smiles>[R6][C@H]1CC[C@@]2(C)C(=CCC3C4CC[C@H]([C@@H](C)CC[C@@H](CC)C(C)C)[C@]4(C)CCC32)C1</smiles>

14: $\mathrm{R}=\mathrm{Glc}$

Figure 1. Compounds 1-14 isolated from $L$. shawii

Emodin (6) has to the best of our knowledge been reported to be present in only one species of the genus Lycium viz., root bark L. chinense [12]. However, the presence of emodin (6) has been found in numerous other plant families; Actinidiaceae, Amaranthaceae, Asteraceae, Bignoniaceae, Clusiaceae, Cupressaceae, Fabaceae, Liliaceae, Myrsinaceae, Plantaginaceae, Poaceae, Polygonaceae, Rhamnaceae, Rosaceae, Saxifragaceae, Simaroubaceae and Vitaceae [21]. Furthermore, the presence of the anthraquinones emodin-8-O- $\beta$-D-glucoside (7), aloe-emodin (8), aloe-emodin- $8-O-\beta$-Dglucoside (9), emodin-11- $O$-rhamnoside (10) and chrysophanol-8- $O-\beta$-D-glucoside (11) were reported, for the first time, from the genus Lycium and family Solanaceae except aloe-emodin (8) which was previously reported from Solanaceae [22]. Interestingly, aloe-emodin (8) has been found to be present in various Cassia species (family Fabaceae) viz., C. absus, C. alata, C. angustifolia, C. didymobotrya, C. fistula, C. grandis, C. italica, C. javanica and C. obtusifolia [23]. Four additional anthraquinones (other than 6-11) have previously been reported from only one species of the genus Lycium viz., L. chinense [12]. The substitution patterns in anthraquinones isolated from $L$. shawii and L. chinense have some common structural feature viz., most of the anthraquinones are 1, 3oxygenated with a methyl group at the C-2 position. Finally, the presence of nonacosane-10-ol (12), betulinic acid (13) and $\beta$-sitosterol glucopyranoside (14) is reported here for the first time being isolated from $L$. shawii. The authors have noted that the latter compound (14) has previously been reported from L. chinense and L. barbarum [12] and Embelia schimperi [24]. Moreover, a number of triterpenoids have been reported as being isolated from the genus Lycium [12]. However, only one lupane-type triterpenoid (lupeol) has been reported from the said genus [12] and betulinic acid (13) 
represents a second example of a lupane-type triterpenoid from the genus Lycium and Calophyllum [25].

The current investigation has shown that the main secondary metabolites identified in $L$. shawii were anthraquinones and sesquiterpenoids, in addition to one flavanol, triterpene and steroid. Interestingly, anthraquinones, sesquiterpenoids, flavanols and steroids, as a collective group have only been reported from one species of Lycium i.e. L. chinense [12]. Of further interest to the authors is the fact that only four additional anthraquinones (other than 6-11) have previously been reported from only one species of the genus Lycium viz., L. chinense [12] and that six anthraquinones 6-11 (major class of compound) have been isolated in the current investigation from $L$. shawii. The authors are of the opinion that isolation of anthraquinones sesquiterpenoids, flavanols and steroids in the current study strongly suggests that $L$. shawii has a similar inherent biosynthetic system to and shares a close genetic relationship with $L$. chinense which might have a collective chemotaxonomic value.

\section{Acknowledgment}

The authors express sincere thanks to The Oman Research Council (TRC) for the financial and generous support through the project (grant number: ORG/HSS/14/004).

\section{Supporting Information}

Supporting information accompanies this paper on http://www.acgpubs.org/RNP

\section{ORCID}

Najeeb Ur Rehman: 0000-0002-1563-225X

Hidayat Hussain: 0000-0002-8654-8127

Samia Ahmed Al-Riyami: 0000-0002-4264-9444

Ivan R. Green: 0000-0002-9158-670X

Ahmed Al-Harrasi: 0000-0002-0815-5942

\section{References}

[1] H.H. Baghdadi, S.H. El-Sayed, G. A. Salem and A. M Metwally (1988). A comparative chemical study of Lycium species growing in Egypt, Alexandria J. Pharm. Sci. 2, 73-76.

[2] N. Rehman, H. Hussain, S.A. Al-Riyami, R. Csuk, M. Khiat, G. Abbas, A. Al-Rawahi, I.R. Green, I. Ahmed and A. Al-Harrasi (2016). Lyciumaside and Lyciumate: A new diacylglycoside and sesquiterpene lactone from Lycium shawii, Hel. Chim. Acta. 99, 632-635.

[3] A. Li, A. Sun and R. Liu (2005). Preparative isolation and purification of costunolide and dehydrocostuslactone from Aucklandia lappa Decne by high-speed counter-current chromatography, $J$. Chromatogr. A. 1076, 193-197.

[4] I. Naz, Saifullah and M.R. Khan (2013). Nematicidal activity of nonacosane-10-ol and 23ahomostigmast-5-en-3 $\beta$-ol isolated from the roots of Fumaria parviflora (Fumariaceae), J. Agric. Food Chem. 61, 5689-5695.

[5] Q. Shu-Hua, W. Da-Gang, M. Yun-Bao and L. Xiao-Dong (2003). A novel flavane from Carapa guianensis, Acta Bot. Sin. 45, 1129-1133.

[6] R.T. Dewi, Minarti, A. Darmawan and H. Mulyani (2008). Proceeding of The International Seminar on Chemistry 731.

[7] A.M. Abd El-Kader, A.M.A. Abd El-Mawla, M.H. Mohamed and Z.Z. Ibraheim (2006). Phytochemical and biological studies of Emex spinosa (L.) campd. growing in Egypt, Bull. Pharm. Sci., Assiut University 29, 328-347.

[8] J.M. Conner, A.I. Gray, T. Reynolds and P.G.Waterman (1989). Anthracene and chromone derivatives in the exudate of Aloe rabiansis, Phytochemistry 28, 3551-3553.

[9] D.H. Kim, E.K. Park, E.A. Bae and M.J. Han (2000). Metabolism of rhaponticin and chrysophanol 8-Obeta-D-glucopyranoside from the rhizome of Rheum undulatum by human intestinal bacteria and their anti-allergic actions, Biol Pharm. Bull. 23, 830-833. 
[10] M.E. Haque, H.U. Shekhar, A.U. Mohamad, H. Rahman, A.M. Islam and M.S. Hossain (2006). Triterpenoids from the stem bark of Avicennia officinalis, Dhaka Univ. J. Pharm. Sci. 5, 53-57.

[11] N.M.M.U. Khan and M.S. Hossain (2015). Scopoletin and $\beta$-sitosterol glucoside from roots of Ipomoea digitata, J. Pharmacog. Phytochem. 4, 5-7.

[12] X. Yao, Y. Peng, L.J. Xu, L. Li, Q.L. Wu and P.G. Xiao (2011). Phytochemical and biological studies of Lycium medicinal plants, Chem. Biodiver. 8, 976-1010.

[13] M. Chadwick, H. Trewin, F. Gawthrop and C. Wagstaff (2013). Sesquiterpenoids lactones: Benefits to Plants and People, Int. J. Mol. Sci. 14, 12780-12805.

[14] B.A. Hess, L. Smentek, J.P. Noel and P.E.O. Maille (2011). Physical constraints on sesquiterpene diversity arising from cyclization of the eudesm-5-yl carbocation, J. Am. Chem. Soc. 133, 1263212641.

[15] A. Robinson, T.V. Kumar, E. Sreedhar, V.G.M. Naidu, S.R. Krishna, K.S. Babu, P.V. Srinivas and J.M. Rao (2008). A new sesquiterpene lactone from the roots of Saussurea lappa: Structure-anticancer activity study, Bioorg. Med. Chem. Lett. 18, 4015-4017.

[16] J.W. de Kraker (2002). PhD Thesis; The Biosynthesis of Sesquiterpene Lactones in Chicory (Cichorium intybus L.) Roots, Wageningen University, Netherlands.

[17] S.H. Bok, E.E. Kim, J.Y. Yoo and M.S. Choi (2014). Anti-obesity composition comprising Lycium chinense leaf extract and betaine as active ingredient, US 201400508104.

[18] K. Helmja, M. Vaher, J. Gorbatšova and M. Kaljurand (2007). Characterization of bioactive compounds contained in vegetables of the Solanaceae family by capillary electrophoresis, Proc. Estonian Acad. Sci. Chem. 56, 172-186.

[19] Y. Ishioka, M. Yagi, M. Ogura and M.Y. Yonei (2015). Polyphenol content of various vegetables: Relationship to antiglycation activity, Glycative Stress Res. 2, 41-45.

[20] G. Renda, A. Ozel, B. Barut, B. Korkmaz, M. Soral, U. Kandemir and T. Liptaj (2018). Bioassay guided isolation of active compounds from Alchemilla barbatiflora Juz, Rec. Nat. Prod. 12, 76-85.

[21] I. Izhaki (2002). Emodin - a secondary metabolite with multiple ecological functions in higher plants. New Phytologist. 155, 205-217.

[22] Q. Chang, Y. Peng, C. Dan, Q. Shuai and S. Hu (2015). Rapid in situ identification of bioactive compounds in plants by in vivo nanospray high-resolution mass spectrometry, J. Agric. Food Chem. 63, 2911-2918.

[23] H. Dave and L. Ledwani (2012). A review on anthraquinones isolated from Cassia species and their applications, Ind. J. Nat. Prod. Res. 3, 291-319.

[24] K. Wabo, G. Zeng, N.H. Tan and P. Tane (2013). A New cytotoxic alkenylresorcinol from Embelia schimperi, Rec. Nat. Prod. 8, 37-40.

[25] N.I. Aminudin, F. Ahmad, M. Taher and R. Mohamed Zulkifli (2016). Cytotoxic and antibacterial activities of constituents from Calophyllum ferrugineum Ridley, Rec. Nat. Prod. 10, 649-653.

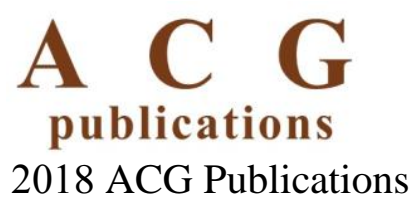

